\title{
Sizing of the Vacuum Vessel Pressure Suppression System of a Fusion Reactor Based on a Water-Cooled Blanket, for the Purpose of the Preconceptual Design
}

\author{
Gianfranco Caruso and Fabio Giannetti \\ Department of Astronautical, Electrical and Energy Engineering, Nuclear Section, Sapienza, University of Rome, \\ C.so Vittorio Emanuele II, 244-00186 Rome, Italy \\ Correspondence should be addressed to Gianfranco Caruso; gianfranco.caruso@uniromal.it
}

Received 31 August 2016; Revised 3 November 2016; Accepted 15 November 2016

Academic Editor: Arkady Serikov

Copyright (C) 2016 G. Caruso and F. Giannetti. This is an open access article distributed under the Creative Commons Attribution License, which permits unrestricted use, distribution, and reproduction in any medium, provided the original work is properly cited.

A methodology to preliminarily evaluate the size of the suppression tank and the relief pipes for a Vacuum Vessel Pressure Suppression System, to be adopted in a fusion reactor based on a water cooled blanket, is presented. The volume of the ST depends on the total energy of the water cooling system and it can be sized based on a required final pressure at equilibrium, by a simple energy balance. The pressure peak in the VV depends mainly on break area and the flow area of the relief pipes and some suggestions about the method for a preliminarily evaluation of their size are discussed. The computer code CONSEN has been used to perform a parametric study and to verify the methodology.

\section{Introduction}

Safety is one of the key issues for fusion energy research [1]. Thermal-hydraulic analysis of possible accidents evaluates system responses to accident scenarios, and it also supports the design of safety systems and strategies to prevent accident propagation or mitigate its consequences [2].

The loss of coolant accident (LOCA) is one of the design basis accidents to be investigated to demonstrate the safety of the fusion plant. In the case of an in-vessel LOCA, water is injected into the vacuum vessel (VV) from the pressurized Primary Heat Transfer System (PHTS), and pressure starts to increase in the VV due to flash evaporation and heating from the structures.

A VV Pressure Suppression System (VVPSS) is designed to avoid overpressurization in the VV and maintain integrity of the primary confinement barrier in cases of ingress of the coolant water in the VV. The volume of the cold water in the VVPSS is estimated so that the hot steam transferred to the storage tank (ST) of the system is condensed. At the end of the discharge phase from the primary circuits, taking also into account other heat sources as the decay heat, the pressure in all the interconnected volumes (PHTS, VV, and VVPSS) must be lower than a required value. This "final" pressure is not the peak value in the VV during the accident, as the maximum pressure occurs in the first seconds after the break and it depends strongly on the sizing of the discharge lines between the VV and the ST and the flow and energy rate at the break.

A preliminary design procedure of the VVPSS could therefore follow two different steps:

(1) Sizing of the ST (total volume and amount of cold water) based on the final pressure at a characteristic time after the break, the water inventory and energy in the PHTS, the total free volume of PHTS + VV + VVPSS, and the heat sources (i.e., decay heat and, eventually, the stored heat in the structures and the heat generated from the exothermic reactions during the accidents).

(2) Sizing of the rupture disk lines and eventual vent lines connecting the VV with the ST of the VVPSS, based on the capability of transferring the energy rate 
entering the VV through the break by a suitable steam flow rate to be condensed in the ST.

The main aim of the present paper is to describe a quite simple methodology for the preliminary sizing of the VVPSS system, to avoid high pressures in the volumes involved in cases of ingress of the coolant water in the VV. The methodology can be easily implemented in a spreadsheet to solve iteratively the equations, using a limited number of input data, so that the procedure could be also utilized for sensitivity purposes. The values of the ST volume and relief piping flow area obtained through the described methodology could be a reliable starting point for future, more detailed, calculations during the design phases of the system.

To verify the sizing procedure, some parametric calculations have been performed by using the CONSEN computer code.

In the past years, due to the lack of proper accident analytical code specifically developed for fusion reactor, safety analytical code developed for fission reactor was modified and adopted for the accident analysis for fusion reactor, both for ITER [3] and for different DEMO models [4, 5].

The CONSEN fast-running code can evaluate temperature and pressure trends in interconnected volumes affected by a loss of coolant accident, taking into account the relative heat and mass exchange. The code solves the equations of mass and energy conservation and evaluates the thermodynamic evolution of the fluids (water, helium, oxygen, nitrogen, and noncondensable gases), including change of phase, also in cryogenic conditions. The critical flow model and the jet impingement heat transfer model are also included into the code. The code allows for heat transfer mechanism such as nucleate and film boiling, critical heat flux evaluation, evaporation at gas-liquid interface, condensation, natural convection, ice formation, and thermal conduction inside the structures. Furthermore, the CONSEN code can also simulate chemical reactions between $\mathrm{Be}, \mathrm{W}, \mathrm{C}$, and steam or air.

The CONSEN code was used in the past for several accident analyses and benchmarks for fusion [6,7] and other code validation programmes, including pre- and posttest calculations for the ICE [8] and EVITA experiments [9]. In [10] a summary of the numerical predictions for EVITA by using the MELCOR, PAX, and CONSEN codes under conditions of steam injection is reported.

\section{Description of the System}

The described methodology refers to the preliminary sizing of VVPSS for a fusion reactor based on a water-cooled blanket, with no reference to a specific fusion reactor design, such as ITER or DEMO preconceptual designs, whose data are available in the literature.

In most of water cooled concepts the first wall, breeding blanket modules and divertor cassettes are cooled by pressurized water of which operation conditions are similar to pressurized light water reactors, that is, the pressure of 15.5 $\mathrm{MPa}$ and the inlet/outlet temperature of $563 / 598 \mathrm{~K}$. The total volume (and, consequently, the water inventory) of the Primary Heat Transfer System (PHTS) in DEMO is to be defined during the design of this system, but we can assume values from $300 \mathrm{~m}^{3}$ (PWR volume) to $1000 \mathrm{~m}^{3}$, at the present stage.

The VVPSS consists mainly of a pressure suppression tank (ST), relief pipes, rupture discs, and bleed lines. In ITER, the ST is a large linear tank circular cross section of $\approx 6 \mathrm{~m}$ diameter, a volume of $\approx 1200 \mathrm{~m}^{3}$ containing $\approx 700 \mathrm{~m}^{3}$ room temperature water to condense the steam resulting from the most adverse in-vessel coolant leak. The VVPSS tank is designed for $200 \mathrm{kPa}$ and constructed in ferrite steel. The tank is connected to the vacuum vessel through three main relief pipes, each pipe incorporating double rupture disc assemblies. The rupture discs are designed to activate in few milliseconds when the pressure in the VV reaches $1.5 \mathrm{bar}$ (now reduced to 1.4 bar). Rupture disc acts as vacuum boundary between the vacuum vessel and the room temperature suppression water during normal operation. In ITER the total relief pipe area requirement is $1.0 \mathrm{~m}^{2}$, in order to maintain vacuum vessel pressure below $200 \mathrm{kPa}$ during an accident. In the design, this flow area is provided by two of the relief pipes, the third being redundant. In each relief line, a bypass system for the rupture discs is also included, for small coolant leaks, equipped with servovalves opening at a pressure of about $90 \mathrm{kPa}$, with a flow area of $0.1 \mathrm{~m}^{2}$. During an in-vessel coolant leak the VVPSS can operate in concert with the vacuum vessel drainage system, which facilitates timely drainage of water from the vacuum vessel to limit the amount of steam that the suppression tank has to condense, for a large coolant leak.

\section{Sizing the ST Volume: Methodology}

The goal of the first step could be achieved by the application of an energy balance between the initial condition before the break and the final, required, thermodynamic conditions in the volumes. The presence of a heat source as the decay heat, in terms of heat power $\dot{Q}$, requires to define a time interval after which the final pressure is reached.

The energy balance between the initial and the final states ( 0 and $f$, resp.) is

$$
E_{0}+\int_{0}^{t_{f}} \dot{Q} d t=E_{f}
$$

where the energies depend on the storage tank volume $V_{\mathrm{ST}}$ and its initial cold water inventory $M_{\mathrm{ST}, 0}$ :

$$
\begin{aligned}
\rho_{l, \mathrm{ST}, 0} & \cdot \alpha \cdot V_{\mathrm{ST}} \cdot h_{\mathrm{ST}, 0}-p_{\mathrm{ST}, 0} \cdot V_{\mathrm{ST}}+M_{\mathrm{PHTS}} \cdot h_{\mathrm{PHTS}, 0} \\
& -p_{\mathrm{PHTS}, 0} \cdot V_{\mathrm{PHTS}}+\int_{0}^{t_{f}} \dot{\mathrm{Q}} d t \\
= & \left(\rho_{l, \mathrm{ST}, f} \cdot \alpha \cdot V_{\mathrm{ST}}+M_{\mathrm{PHTS}}\right) \cdot h_{f}-p_{f} \\
& \cdot\left(V_{\mathrm{ST}}+V_{\mathrm{VV}}+V_{\mathrm{PHTS}}\right) .
\end{aligned}
$$

In the previous energy balance, the air mass in the $\mathrm{VV}$ and the VVPSS has been neglected, due to its limited amount and energy contribution, if an air ingress is excluded: therefore, the initial ST pressure $p_{\mathrm{ST}, 0}$ is the water saturation pressure 
TABLE 1: Reference and sensitivity values in the parametric analyses.

\begin{tabular}{lcc}
\hline Parameter & Reference value & Sensitivity values \\
\hline Primary HTS volume & $300 \mathrm{~m}^{3}$ & $600 \mathrm{~m}^{3} ; 1000 \mathrm{~m}^{3}$ \\
$\begin{array}{l}\text { ST temperature } \\
\begin{array}{l}\text { ST liquid volume } \\
\text { fraction }\end{array}\end{array}$ & $293.15 \mathrm{~K}$ & $303.15 \mathrm{~K} ; 313.15 \mathrm{~K}$ \\
$\begin{array}{l}\text { Decay heat (assumed } \\
\text { constant) }\end{array}$ & 0.5 & $0.6 ; 0.7 ; 0.8$ \\
\hline
\end{tabular}

only. Otherwise, air can easily be considered in (2). The initial steam content in the ST can be also neglected, and the initial water mass $M_{\mathrm{ST}, 0}$ is considered as liquid in the energy balance.

At the required final conditions " $f$," the average enthalpy $h_{f}$ is calculated as $h_{l, f}+\left(h_{v, f}-h_{l, f}\right) \cdot x_{f}$, where the final quality $x_{f}$ is the average value in the whole available volume and it is calculated as

$$
\begin{aligned}
& x_{f} \\
& =\frac{\left(V_{\mathrm{ST}}+V_{\mathrm{VV}}+V_{\mathrm{PHTS}}\right) /\left(\rho_{l, \mathrm{ST}, f} \cdot \alpha \cdot V_{\mathrm{ST}}+M_{\mathrm{PHTS}}\right)-v_{l, f}}{\left(v_{v, f}-v_{l, f}\right)} .
\end{aligned}
$$

Therefore, the (minimum) volume of the suppression tank $V_{\mathrm{ST}}$, to assure at the time $t_{f}$ after the break a final pressure in the system lower than the required value $p_{f}$, can be obtained by the energy balance (2). The following variables must be known: the VV volume, the PHTS water inventory and its thermodynamic conditions, the ST temperature and filling fraction, and the heat source.

The described procedure can be easily implemented in a spreadsheet, provided that the "goal seek" function and thermodynamic properties of water are available.

Assuming a VV volume $V_{\mathrm{VV}}=2240 \mathrm{~m}^{3}$, with reference to a typical value of a DEMO design, a pressure/temperature in the PHTS $p_{\mathrm{PHTS}, 0}=15.5 \mathrm{MPa} / T_{\mathrm{PHTS}, 0}=598 \mathrm{~K}$ (similar to PWRs, as described in Section 2), and a required final pressure of the system $p_{f}=150 \mathrm{kPa} 1 \mathrm{~h}$ after the break, a sensitivity analysis can be performed to evaluate the minimum ST volume at different conditions for other parameters.

In Table 1, the reference values and those adopted in the parametric calculations performed for the other variables are reported.

The Primary Heat Transfer System volume has been preliminary assumed in analogy with a typical PWR primary loop. Due to the peculiar characteristic of a fusion reactor plant and its BOP, a sensitivity study using two higher values of this volume has been performed.

Concerning the ST temperature, the higher its value is, the higher the needed inventory of cold water to absorb the energy by condensation will be.

About the ST filling fraction, the typical value of 0.5 has been assumed as reference (a similar value was used in ITER). This value is needed to have a sufficient free volume to accommodate the condensed steam, the pool swelling during the discharge, and, mainly, the eventual air mass drained with the steam flow from the volume to protect. In this case, as

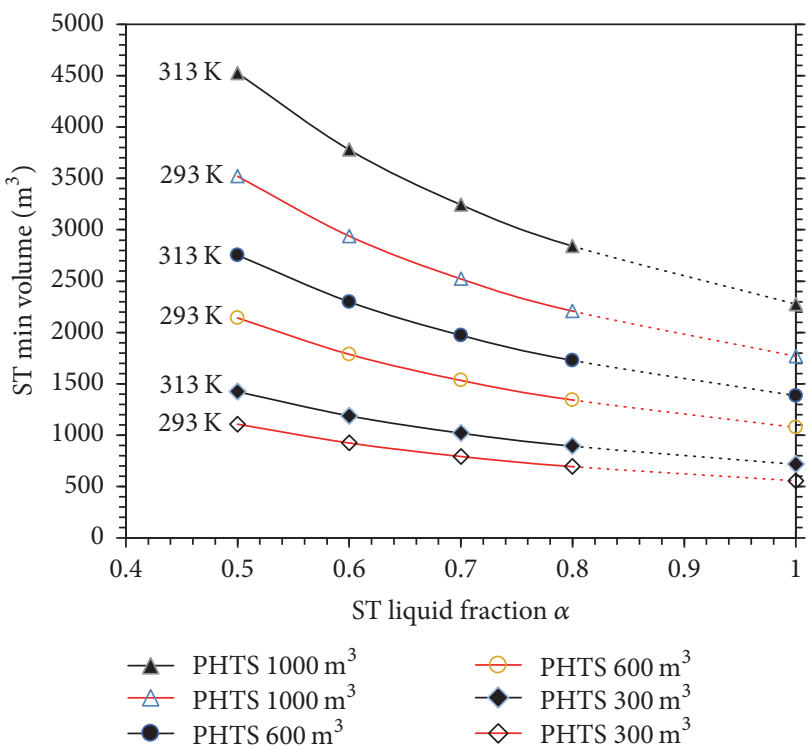

FIgURE 1: Minimum ST volume.

the air (gas) content in a fusion reactor is very low, due to the near vacuum pressures needed in the system, a greater filling fraction in the ST can be hypothesized, reducing the total volume $V_{\mathrm{ST}}$ without affecting the cold water inventory, which mainly determines the final pressure.

With the only purpose to present the methodology, the heat source (i.e., decay heat and, eventually, the stored heat in the structures and the heat generated from the exothermic reactions during the accidents, as previously reported) has been assumed constant in the first hour after the break. A reference value of $5 \mathrm{MW}$ could be reasonable, but higher values have been investigated to evaluate the effect on the ST sizing.

\section{Sizing the ST Volume: Results and Discussion}

Assuming a constant heat source of $5 \mathrm{MW}$ for $1 \mathrm{~h}$, some results of the parametric calculations are reported in Figure 1. The volume corresponding to $\alpha=1$ is, obviously, representative of the minimum liquid inventory needed in the ST. For clarity, only two ST temperatures are shown in the figure, providing the intermediate temperature $(303.15 \mathrm{~K})$ results averaged between the minimum and maximum temperatures reported.

Analyzing the results, the increase in \% of the minimum $V_{\mathrm{ST}}$ with the water temperature is $1.25 \% \Delta V / V$ per K between 293.15 and $303.15 \mathrm{~K}$ and $1.43 \%$ in the range $303.15-313.15 \mathrm{~K}$, constant for all the PHTS volume and water fraction in the $\mathrm{ST}$. Thus, as $V_{\mathrm{ST}}$ increase with the PHTS volume (as a greater thermal energy must be absorbed by the cold water through condensation of steam) and decreasing the filling fraction $\alpha$ (the liquid volume depends mainly from the PHTS volume), also the absolute volume increment is larger for low $\alpha$ and high PHTS volume. 
TABle 2: Minimum ST volume in $\mathrm{m}^{3}$.

\begin{tabular}{|c|c|c|c|c|c|c|c|c|c|c|c|c|c|}
\hline & \multirow{2}{*}{$\begin{array}{l}\text { PHTS vol. } \\
\text { ST liq. } \alpha\end{array}$} & \multicolumn{4}{|c|}{$300 \mathrm{~m}^{3}$} & \multicolumn{4}{|c|}{$600 \mathrm{~m}^{3}$} & \multicolumn{4}{|c|}{$1000 \mathrm{~m}^{3}$} \\
\hline & & 0.5 & 0.6 & 0.7 & 0.8 & 0.5 & 0.6 & 0.7 & 0.8 & 0.5 & 0.6 & 0.7 & 0.8 \\
\hline ST temp & Heat source & & & & & & & & & & & & \\
\hline \multirow{4}{*}{293.15} & $5 \mathrm{MW}$ & 1107 & 924 & 793 & 695 & 2142 & 1788 & 1534 & 1343 & 3521 & 2939 & 2522 & 2208 \\
\hline & $10 \mathrm{MW}$ & 1201 & 1003 & 860 & 753 & 2236 & 1866 & 1601 & 1402 & 3615 & 3017 & 2589 & 2267 \\
\hline & $15 \mathrm{MW}$ & 1295 & 1081 & 927 & 812 & 2329 & 1944 & 1668 & 1461 & 3709 & 3095 & 2656 & 2326 \\
\hline & $20 \mathrm{MW}$ & 1389 & 1159 & 995 & 871 & 2423 & 2022 & 1735 & 1520 & 3802 & 3174 & 2723 & 2385 \\
\hline \multirow{4}{*}{303.15} & $5 \mathrm{MW}$ & 1246 & 1040 & 892 & 782 & 2409 & 2011 & 1726 & 1512 & 3961 & 3306 & 2837 & 2485 \\
\hline & $10 \mathrm{MW}$ & 1351 & 1128 & 968 & 848 & 2515 & 2099 & 1802 & 1578 & 4066 & 3394 & 2913 & 2551 \\
\hline & $15 \mathrm{MW}$ & 1457 & 1216 & 1044 & 914 & 2620 & 2187 & 1877 & 1644 & 4172 & 3482 & 2989 & 2617 \\
\hline & $20 \mathrm{MW}$ & 1562 & 1304 & 1119 & 980 & 2726 & 2275 & 1953 & 1710 & 4277 & 3570 & 3064 & 2684 \\
\hline \multirow{4}{*}{313.15} & $5 \mathrm{MW}$ & 1423 & 1189 & 1020 & 894 & 2753 & 2299 & 1973 & 1728 & 4526 & 3779 & 3244 & 2841 \\
\hline & $10 \mathrm{MW}$ & 1544 & 1289 & 1107 & 969 & 2874 & 2399 & 2060 & 1804 & 4646 & 3880 & 3330 & 2917 \\
\hline & $15 \mathrm{MW}$ & 1665 & 1390 & 1193 & 1045 & 2994 & 2500 & 2146 & 1880 & 4767 & 3980 & 3417 & 2993 \\
\hline & $20 \mathrm{MW}$ & 1785 & 1490 & 1279 & 1121 & 3115 & 2601 & 2232 & 1955 & 4887 & 4081 & 3503 & 3068 \\
\hline
\end{tabular}

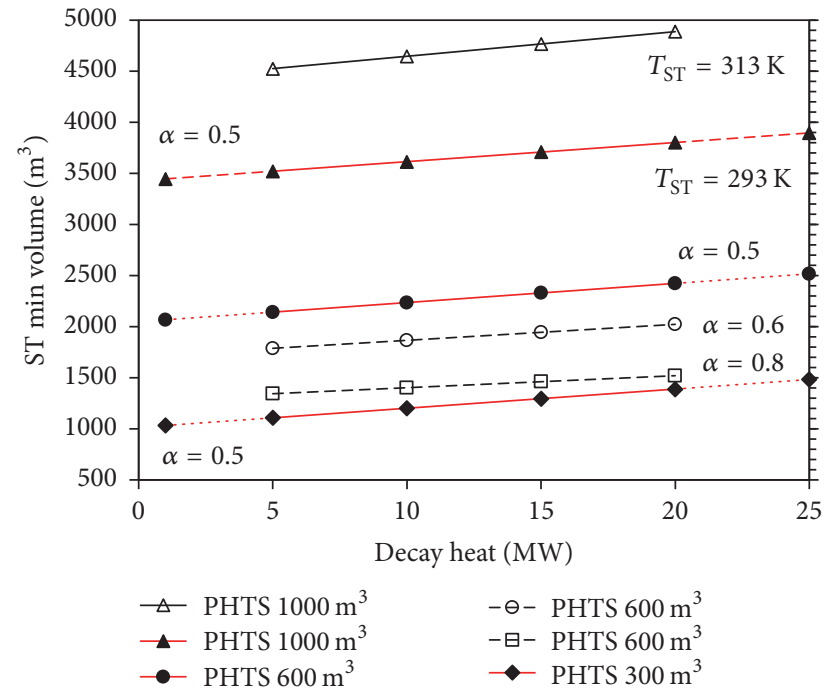

Figure 2: Sensitivity analysis on the decay heat.

In Figure 2, the influence of the heat source on the minimum volume of the suppression tank is shown. As for the previous parameter, the percentage increase $\% \Delta V / V$ per $1 \mathrm{MW}$ of heat is discussed. This value depends mainly on the PHTS volume, and it is $0.85 \% / \mathrm{MW}$ in case of a $300 \mathrm{~m}^{3}$ PHTS, $0.43 \% / \mathrm{MW}$ for $600 \mathrm{~m}^{3}$, and $0.27 \% / \mathrm{MW}$ for $1000 \mathrm{~m}^{3}$ PHTS volume, for all the ST temperatures and liquid fraction $\alpha$. Thus, having the ST volume approximately a linear dependence from the PHTS volume, the absolute change of the $V_{\mathrm{ST}}$ minimum value is quite constant for all PHTS volumes, at a fixed filling fraction and temperature of the ST. This absolute increase is slightly lower as the liquid fraction increases (see $600 \mathrm{~m}^{3}$ in Figure 2 for three different $\alpha$ ) and slightly higher as the ST temperature increases (see $1000 \mathrm{~m}^{3}$ in Figure 2 for two different temperatures).

The results of the sensitivity analysis are reported in Table 2.
A simple correlation to evaluate the minimum $V_{\mathrm{ST}}$ without solving iteratively (2) has been developed through regression of 511 different solutions in the selected range of the parameters, valid only for the conditions: $V_{\mathrm{VV}}=2240 \mathrm{~m}^{3}$, PHTS pressure $p_{\text {PHTS }, 0}=15.5 \mathrm{MPa}$ at $598 \mathrm{~K}$, and a final pressure of the system $p_{1}=150 \mathrm{kPa}, 1 \mathrm{~h}$ after the break. The correlation is

$$
V_{\mathrm{ST}}=K \cdot \dot{Q}^{a} \cdot\left(\frac{V_{\mathrm{PHTS}}}{100}\right)^{b} \cdot \alpha^{c}\left(\frac{T_{\mathrm{ST}}}{373.15}\right)^{d}\left[\mathrm{~m}^{3}\right] .
$$

The correlation presents a coefficient of determination $R^{2}=$ 0.99846 , with a standard error of $2.37 \%$.

The coefficients are $K=487.34 ; a=0.07251 ; b=0.90484$; $c=-0.9954 ; d=-0.7188$

The maximum underestimation of the minimum ST volume is $-7 \%$ in a few cases (4\%) and the error is between $\pm 4 \%$ for $92 \%$ of the analysed cases in the following ranges: $300 \mathrm{~m}^{3} \leq V_{\text {PHTS }} \leq 1000 \mathrm{~m}^{3} ; 0.5 \leq \alpha \leq 0.8 ; 293.15 \mathrm{~K} \leq T_{\mathrm{ST}} \leq$ $313.15 \mathrm{~K} ; 5 \mathrm{MW} \leq \dot{Q} \leq 20 \mathrm{MW}$. Some tests with one or more parameters out of this range provided good results, but with error up to $\pm 12 \%$ in a few cases, as shown in Figure 3 .

\section{Break Area Estimation}

To provide an example of application of the methodology, an estimation of the break area in a typical LOCA is needed.

An initiator of the accident is a multiple double-ended break of the FW cooling pipes in the VV. The runaway electrons generated by plasma disruption might cause such a situation and a surface of $10 \mathrm{~m}^{2}$ of the FW (mainly EUROFER plus a tungsten liner) has been estimated to melt, with the consequent break of the underlying cooling channels. The number of channels affected depends on the location of the melting zone. A rough estimation can be done considering different distributions of the melting zone. With reference to the most recent ENEA design of the WCLL blanket for DEMO [11], the damaged modules could be full $3 \mathrm{OB}$ modules (if the damaged zone is centered on a segment or on the 


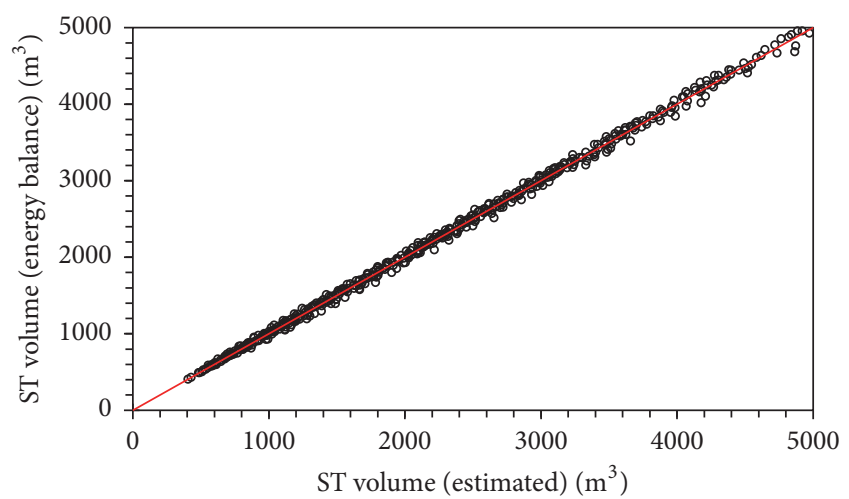

FIGURE 3: Estimated ST volume versus the volume calculated by the energy balance.

equatorial modules) or $6 \mathrm{OB}$ modules (if the damaged zone is centered between two adjacent segments), including the equatorial one (OB4) and the two closest modules (in the same segment-OB3 and OB5-or in the adjacent segments). Furthermore, we can also conservatively assume that all the OB blanket modules at the equatorial plane along the toroidal circumference were damaged. Thus, a toroidal strip $(75.39 \mathrm{~m}$ long, the $\mathrm{OB}$ toroidal perimeter at the equatorial plane, and $0.132 \mathrm{~m}$ width, for a total of $\left.10 \mathrm{~m}^{2}\right)$ is damaged: being $13.5 \mathrm{~mm}$ the pitch of the horizontal cooling square channels $(7 \times 7 \mathrm{~mm})$, a maximum of 10/11 channels per module are affected by the melting along the $54 \mathrm{OB}$ equatorial modules.

Finally, the total number of affected channel could be from 540 to 1134 . Being the flow area of each channel $0.000049 \mathrm{~m}^{2}$ and considering the double flow after their rupture, the break area towards the $\mathrm{VV}$ could be assumed, in a first approximation, between 0.053 and $0.11 \mathrm{~m}^{2}$.

The pressure dynamics inside the VV and its peak value depend strongly from the break flow area and the capability of the relief pipes to discharge an adequate flow of steam into the ST.

\section{Pressure Peak in the VV}

The relief system includes two vent lines (see Section 2), equipped with Safety Relief Valves, for small flow rates, which opens at a differential pressure of $0.09 \mathrm{MPa}$. To face large LOCA situations, a rupture disk in the main relief pipe segments the VV and VVPSS zones, which is assumed to break at the differential pressure of $0.15 \mathrm{MPa}$.

In analogy with ITER, a relief pipe with a flow area of $1 \mathrm{~m}^{2}$ with a rupture disk and two vent lines $\left(0.1 \mathrm{~m}^{2} \times 2\right)$ have been preliminary considered to evaluate the pressure peak in the VV.

A parametric analysis has been performed using $\mathrm{CON}$ SEN for 3 different PHTS volumes $\left(300,600\right.$, and $\left.1000 \mathrm{~m}^{3}\right)$, 3 liquid fraction in the ST $(0.5,0.6$, and 0.7$)$, temperature of liquid in the ST of $293 \mathrm{~K}$, and $5 \mathrm{MW}$ as constant decay heat. The corresponding ST volumes were calculated according the energy balance (2) to obtain a $p_{f}=150 \mathrm{kPa}$ in the system after 1 hour. The break area considered in these calculations is $0.11 \mathrm{~m}^{2}$.

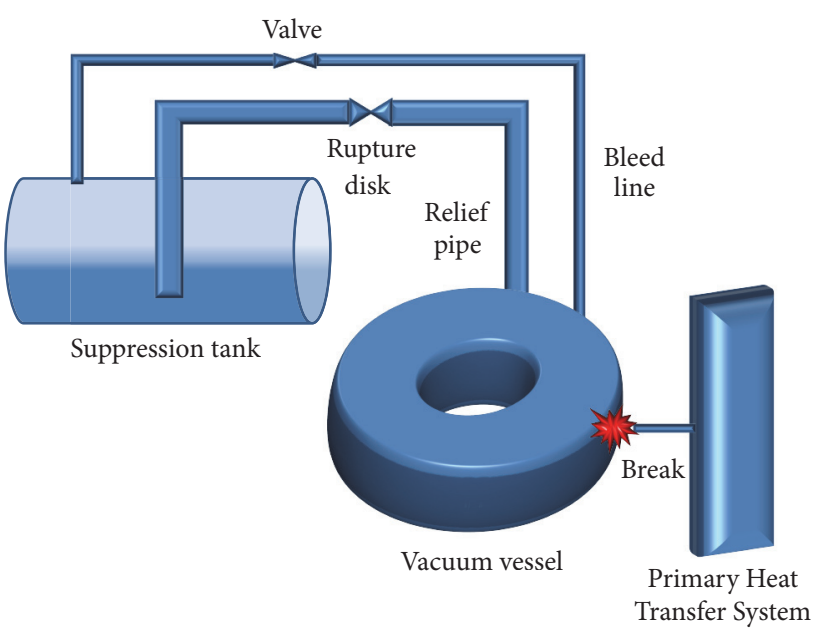

FIGURE 4: VVPSS schematic model in CONSEN calculations.

TABLE 3: Sensitivity analyses to evaluate the pressure peak in the VV.

\begin{tabular}{lccc}
\hline Case & PHTS vol. $\mathrm{m}^{3}$ & Liq. fraction in ST & ST volume $\mathrm{m}^{3}$ \\
\hline A1 & \multirow{2}{*}{300} & 0.7 & 793 \\
A2 & & 0.6 & 924 \\
A3 & & 0.5 & 1107 \\
\hline B1 & \multirow{2}{*}{600} & 0.7 & $1534(1788 ; 3521)$ \\
B2 & & 0.6 & 1788 \\
B3 & & 0.5 & 2142 \\
\hline C1 & \multirow{2}{*}{1000} & 0.7 & 2522 \\
C2 & & 0.6 & 2939 \\
C3 & & 0.5 & 3521 \\
\hline
\end{tabular}

The CONSEN model includes the VV volume $\left(2240 \mathrm{~m}^{3}\right)$, simulated as a horizontal cylinder with a diameter of $7.38 \mathrm{~m}$ and $52 \mathrm{~m}$ long, connected with the PHTS through a break of $0.11 \mathrm{~m}^{2}$ and a concentrated pressure drop coefficient $K=5$, where the cooling water is at $15.5 \mathrm{MPa}$ and $598 \mathrm{~K}$.

The relief pipe and vent lines are $50 \mathrm{~m}$ long, with $K=3.5$ and distributed pressure drops calculated by the code.

The suppression tank is a horizontal cylinder whose diameter is $5.64 \mathrm{~m}$ and the length is variable according to the adopted volume. Relief pipes in the ST have a discharge area (assumed equal to the pipe area) at $1 \mathrm{~m}$ above the bottom of the tank and then a submergence of about $1.8 \mathrm{~m}$.

The presence of a drain tank or a further expansion volume connected to the ST is not considered in the present analyses. The opening time of the burst disks and the SRVs has been also neglected.

In Figure 4 a schematic representation of the system modelized in CONSEN is shown.

The parameters of the calculations are summarized in Table 3.

In Figure 5 the results for cases A3, B3, and C3 (see Table 2) are reported. Similar results were obtained with different liquid fraction in the ST, as the adopted volume of the tank in all the cases was calculated according to the criterion of a similar final pressure in the system. 


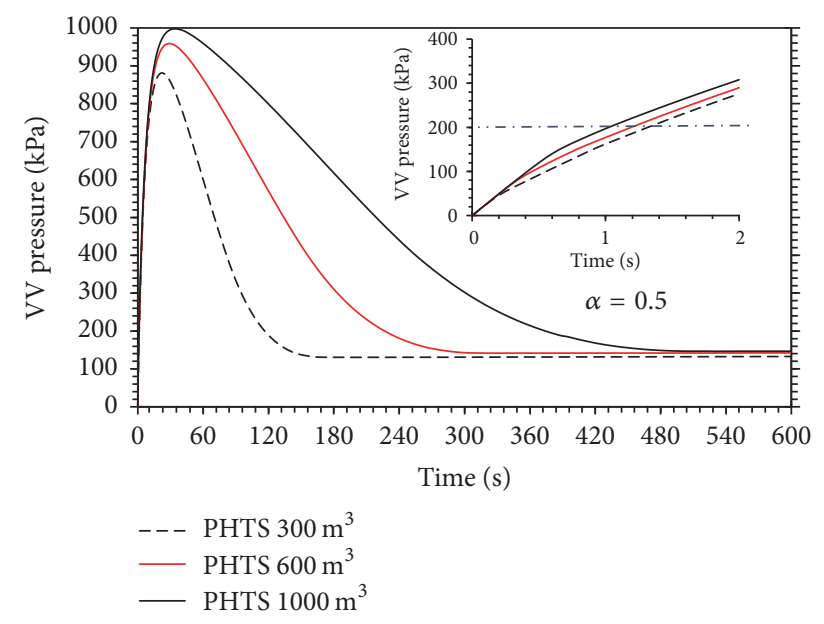

FIGURE 5: Sensitivity analysis on the PHTS volume.

The pressure peaks in all cases are higher than the limit of $200 \mathrm{kPa}$ for the integrity of the $\mathrm{VV}$. The peak is $881 \mathrm{kPa}$ at $21.5 \mathrm{~s}$ (PHTS $300 \mathrm{~m}^{2}$ ), $958 \mathrm{kPa}$ at $28.5 \mathrm{~s}$ (PHTS $600 \mathrm{~m}^{3}$ ), and $998 \mathrm{kPa}$ at $33.5 \mathrm{~s}$ (PHTS $1000 \mathrm{~m}^{3}$ ). Higher pressure peak occurs when there is a larger unbalance between the inlet and outlet energy flow in the VV: since higher flow rates derive from larger PHTS volumes, as their pressure drops less quickly, and the critical flow of steam discharged from the VV to the ST is strictly related to the relief flow area (which is the same in all the cases), it is demonstrated, as expected, that the pressure peak value is strongly affected by this last parameter.

It can be noted that, with the suitable volume for the ST deduced by the energy balance (2), the pressure after the peak, in the 3 cases, tends to the same predicted value $(150 \mathrm{kPa})$. A further sensitivity, for the case B1 but adopting ST volumes higher than suggested by the energy balance, is shown in Figure 6: as expected also in this situation, the transient to the peak pressure is the same and the "equilibrium" pressure will be lower as the ST volume is higher.

In Figures 7 and 8 the flow rates from the PHTS and from VV to the ST are shown, respectively. The flow rates follow the pressure trends in the respective origin volumes, as they are in critical conditions. Oscillations in Figure 8 are caused by a too large time step used in that time interval, when the pressures in the volumes are quite close. Therefore, they have no physical meaning and could be reduced by using a smaller time step.

Therefore, a simple method to evaluate the needed relief flow area is now analysed.

6.1. Sizing the Relief Flow Area: Methodology. In Figure 5, in the small frame, the pressure transient in the first 2 seconds after the break is shown. It can be noted that the time interval between the opening pressure of the rupture disk $(150 \mathrm{kPa})$ and the pressure limit $(200 \mathrm{kPa})$ is about $0.2-0.3 \mathrm{~s}$, a very short time, despite the fact that the rupture disk is assumed to open in $10 \mathrm{~ms}$.

Therefore, to avoid a pressure increment in the VV, at the time of opening the relief line the energy flow coming from

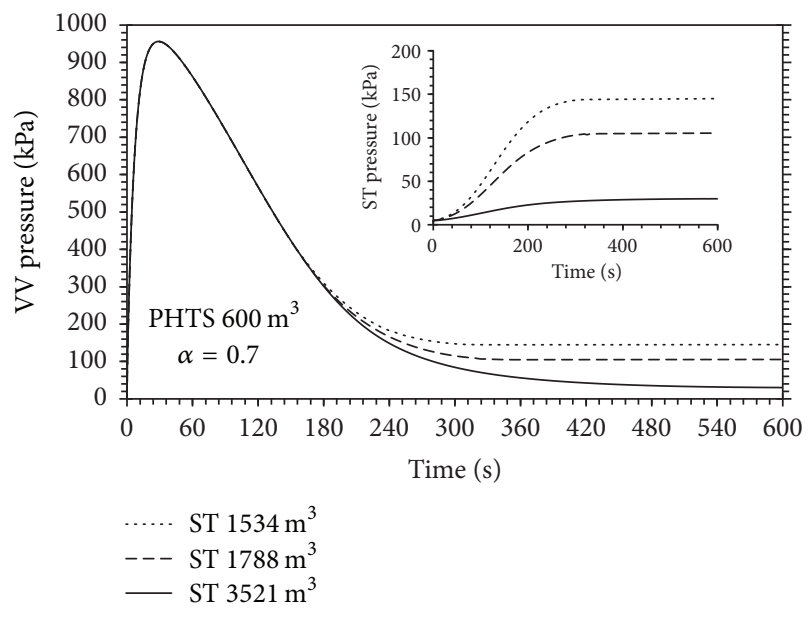

FIGURE 6: Sensitivity analysis on the ST volume.

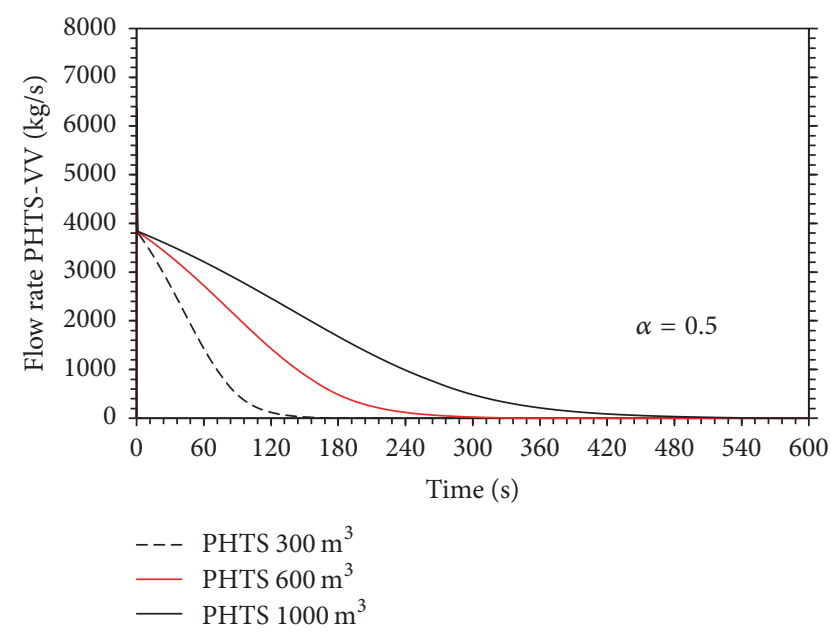

Figure 7: Flow rate from the break $\left(0.11 \mathrm{~m}^{2}\right)$.

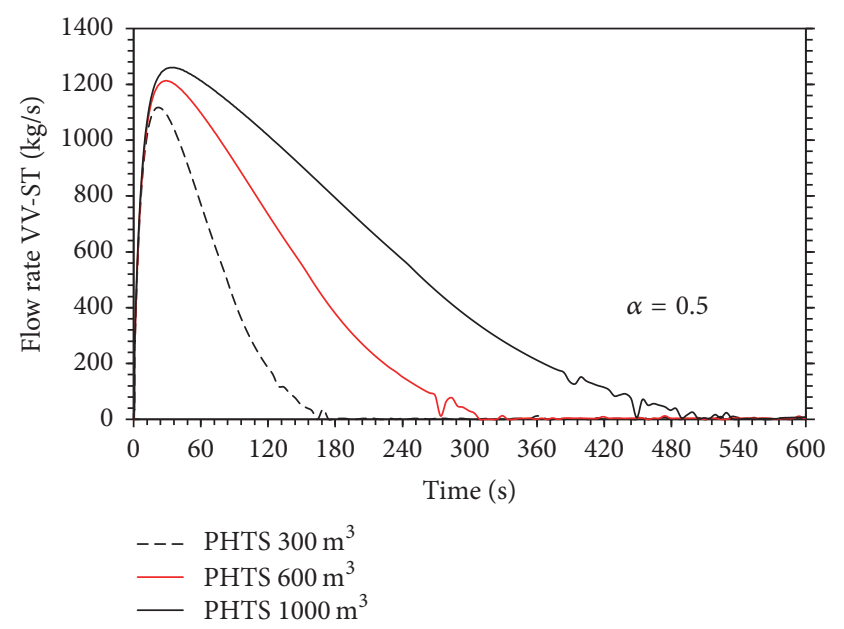

FIGURE 8: Flow rate through the relief and vent pipes (total area $1.2 \mathrm{~m}^{2}$ ). 
the PHTS must be equated by an energy flow from the VV to the ST through the discharged steam. At that time (0.6$0.8 \mathrm{~s}$ after the break), the PHTS pressure is dropped to the saturation pressure at a temperature few degrees lower than the initial temperature and the fluid at the break is saturated liquid.

Therefore, a saturated liquid critical flow occurs at the break and the flow rate $\Gamma_{l \text {,PHTs }}$ could be estimated by suitable models. At the same time, steam in the VV will be discharged to the ST in saturated steam critical flow conditions, and in this case, also the mass velocity $\mathrm{G}_{v, \mathrm{VV}}$ can be evaluated by a simple model.

If the steam flow rate $\Gamma_{v, \mathrm{VV}}$ is evaluated by an energy balance, requiring the constant pressure in the $\mathrm{VV}$, despite a variable inventory of water in it, the relief flow area $A_{\mathrm{RL}}$ will be evaluated as

$$
A_{\mathrm{RL}}=\frac{\Gamma_{v, \mathrm{VV}}}{G_{v, \mathrm{VV}}} .
$$

The simplified energy conservation equation in transient conditions is

$$
\frac{d(M \cdot u)_{\mathrm{VV}}}{d t}=\Gamma_{l, \mathrm{PHTS}} \cdot h_{l, \mathrm{PHTS}}-\Gamma_{v, \mathrm{VV}} \cdot h_{v, \mathrm{VV}}
$$

where $u$ is the specific internal energy in the VV. Using the mass conservation equation,

$$
\frac{d M_{\mathrm{VV}}}{d t}=\Gamma_{l, \mathrm{PHTS}}-\Gamma_{v, \mathrm{VV}}
$$

and requiring a constant pressure in the $\mathrm{VV}$ in saturation condition (from which the specific enthalpy and specific volume of steam and liquid are constant), after some simple manipulation of (6), the required steam flow to satisfy the balance is

$$
\Gamma_{v, \mathrm{VV}}=\frac{\Gamma_{l, \mathrm{PHTS}} \cdot\left(h_{l, \mathrm{PHTS}}-H\right)}{h_{v, \mathrm{VV}}-H},
$$

where the specific enthalpy $H$ is

$$
H=\frac{h_{l, \mathrm{VV}} \cdot v_{v, \mathrm{VV}}-h_{v, \mathrm{VV}} \cdot v_{l, \mathrm{VV}}}{v_{v, \mathrm{VV}}-v_{l, \mathrm{VV}}} .
$$

The break flow rate $\Gamma_{l, \text { PHTS }}$ can be estimated with the "omega"model from Leung [12], developed for sizing relief valves, here reported for the specific case of a saturated liquid discharge in critical conditions. This methodology is adopted in CONSEN.

The critical pressure is evaluated with the following equation:

$$
\begin{gathered}
\left(\frac{p_{c}}{p_{\text {PHTS }}}\right)^{2}+\left(\omega^{2}-2 \cdot \omega\right) \cdot\left(1-\frac{p_{c}}{p_{\text {PHTS }}}\right)^{2}+2 \cdot \omega^{2} \\
\cdot \ln \frac{p_{c}}{p_{\text {PHTS }}}+2 \cdot \omega^{2} \cdot\left(1-\frac{p_{c}}{p_{\text {PHTS }}}\right)=0
\end{gathered}
$$

where the compressibility parameter $\omega$ for saturated liquid is (thermodynamic properties at the PHTS pressure)

$$
\omega=\frac{c_{p} \cdot T_{\text {PHTS }} \cdot p_{\text {PHTS }}}{v_{l}} \cdot\left(\frac{v_{v}-v_{l}}{h_{v}-h_{l}}\right)^{2} .
$$

The mass flow rate is then evaluated with the following equation:

$$
\begin{aligned}
\Gamma_{l, \mathrm{PHTS}} & =A_{\mathrm{BRK}} \cdot \sqrt{\frac{p_{\mathrm{PHTS}}}{v_{l}}} \\
& \frac{\sqrt{-2 \cdot\left[\omega \cdot \ln \left(p_{c} / p_{\mathrm{PHTS}}\right)+(\omega-1) \cdot\left(1-p_{c} / p_{\mathrm{PHTS}}\right)\right]}}{\omega \cdot\left(p_{\mathrm{PHTS}} / p_{c}-1\right)+1} .
\end{aligned}
$$

A different model to evaluate the critical flow can be used, obtaining different results, if low subcooling or saturated conditions occur in the pressurized volume, but this does not affect the validity of the methodology, in particular of (8).

Therefore, the required steam flow rate is calculated by (8) and the mass velocity in critical condition is evaluated by the simple ideal gas equation, being the ST at a very low pressure (4200 Pa), largely below the critical pressure:

$$
G_{v, \mathrm{VV}}=\sqrt{\gamma \cdot \frac{p_{\mathrm{RL}}}{v_{v}} \cdot\left(\frac{2}{\gamma+1}\right)^{(\gamma+1) /(\gamma-1)}}
$$

where $\gamma=C_{p} / C_{v}$ for steam is 1.3 and $p_{\mathrm{RL}}$ is the pressure in the relief pipe, considering the pressure drops between the $\mathrm{VV}$ and before the outlet section of the relief pipe. These pressure drops can be evaluated as

$$
\Delta p_{\mathrm{RL}}=p_{\mathrm{VV}}-p_{\mathrm{RL}}=\frac{1}{2} \cdot K \cdot \frac{G_{v, \mathrm{VV}}^{2}}{\rho_{v}},
$$

where the $K$ includes both localized and distributed pressure drops coefficients, assumed, in a first approximation, constant. Equations (13) and (14) shall be solved iteratively in a spreadsheet.

Finally, the relief flow area is obtained by (5).

A numerical example of application of the procedure, implemented in a spreadsheet, is now reported. Assuming $p_{\text {PHTS }}=11.56 \mathrm{MPa}$ (i.e., the saturation pressure at $595 \mathrm{~K}$, three degrees lower than the initial maximum PHTS temperature $598 \mathrm{~K}$, immediately after the break pressure in the PHTS drops at the saturation value corresponding to a temperature few degrees lower than the initial value), the VV pressure $200 \mathrm{kPa}$ and a break area of $0.11 \mathrm{~m}^{2}$, from (10) and (11) are as follows:

$$
\begin{aligned}
\frac{p_{c}}{p_{\text {PHTS }}} & =0.76 \\
\omega & =3.688
\end{aligned}
$$

and the break flow rate is calculated by (12):

$$
\Gamma_{l, \mathrm{PHTS}}=3810 \mathrm{~kg} / \mathrm{s} \text {. }
$$


From (8),

$$
\Gamma_{v, \mathrm{VV}}=1724.68 \mathrm{~kg} / \mathrm{s} .
$$

From (13) and (14), with an iterative procedure,

$$
\begin{aligned}
\mathrm{G}_{v, \mathrm{VV}} & =237.9 \mathrm{~kg} / \mathrm{m}^{2} \mathrm{~s} \\
p_{\mathrm{RL}} & =150.3 \mathrm{kPa} .
\end{aligned}
$$

And, finally, from (5),

$$
A_{\mathrm{RL}}=7.25 \mathrm{~m}^{2}
$$

In the same conditions, a break area of $0.053 \mathrm{~m}^{2}$ leads to a relief flow area of $3.5 \mathrm{~m}^{2}$.
The pressure peak in the VV is related to the energy and mass balances between the flow from the break (in) and the discharged flow through the relief piping (out). The energy balance in (6) can be used to evaluate the pressure peak in the $\mathrm{VV}$ as a function of the ratio $A_{\mathrm{RL}} / A_{\mathrm{BRK}}$ :

$$
\begin{aligned}
\frac{d(M \cdot u)_{\mathrm{VV}}}{d t}= & \left(M \cdot \frac{d u}{d t}+u \cdot \frac{d M}{d t}\right)_{\mathrm{VV}} \\
= & \Gamma_{l, \mathrm{PHTS}} \cdot h_{l, \mathrm{PHTS}}-\Gamma_{v, \mathrm{VV}} \cdot h_{v, \mathrm{VV}} \\
= & G_{\mathrm{BRK}} \cdot A_{\mathrm{BRK}} \cdot h_{l, \mathrm{PHTS}}-G_{v, \mathrm{VV}} \cdot A_{\mathrm{RL}} \\
& \cdot h_{v, \mathrm{VV}} \cdot
\end{aligned}
$$

At the pressure peak $d u / d t=0$ and being $d M / d t=\Gamma_{l, \text { PHTS }}-$ $\Gamma_{v, \mathrm{VV}}$, after some manipulation (20) provides

$$
H\left(p_{v v, \text { peak }}\right)=\frac{G_{\mathrm{BRK}} \cdot h_{l, \mathrm{PHTS}}-G_{v, \mathrm{VV}}\left(p_{\mathrm{VV}, \text { peak }}\right) \cdot\left(A_{\mathrm{RL}} / A_{\mathrm{BRK}}\right) \cdot h_{v, \mathrm{VV}}\left(p_{\mathrm{VV}, \text { peak }}\right)}{G_{\mathrm{BRK}}-G_{v, \mathrm{VV}}\left(p_{\mathrm{VV}, \text { peak }}\right) \cdot\left(A_{\mathrm{RL}} / A_{\mathrm{BRK}}\right)},
$$

where the specific enthalpy $H$, evaluated at the peak pressure $p_{\mathrm{VV}, \text { peak }}$, is defined as in (9). In the above equation, the discharge mass velocity $G_{v, \mathrm{VV}}$ is also a function of the unknown pressure peak in the VV, according to (13) and (14). Solving iteratively (21), the value of the pressure peak could be obtained as a function of the area ratio $A_{\mathrm{RL}} / A_{\mathrm{BRK}}$ and the break saturated liquid flow $G_{\mathrm{BRK}}$ at the PHTS pressure.

In Figure 9 the results for two different break mass velocities are shown, for $p_{\text {PHTS }}=11.56 \mathrm{MPa}$ (saturation pressure in the PHTS, few seconds after the break).

For a break mass velocity $G_{\mathrm{BRK}}=34640 \mathrm{~kg} / \mathrm{m}^{2} \mathrm{~s}$, corresponding to a mass flow rate $\Gamma_{l, \mathrm{PHTS}}=3810 \mathrm{~kg} / \mathrm{s}$ as in the previous numerical example for a break of $0.11 \mathrm{~m}^{2}$, the area ratio to limit the pressure in the $\mathrm{VV}$ at $200 \mathrm{kPa}$ is about 66 , corresponding to a relief area $A_{\mathrm{RL}}=7.26 \mathrm{~m}^{2}$, as previously calculated. Due to the uncertainty in the critical flow calculations by using different models, if a break mass velocity of $53950 \mathrm{~kg} / \mathrm{m}^{2} \mathrm{~s}$ is used, an area ratio of 100 is obtained, with a relief area of $11 \mathrm{~m}^{2}$.

Data from Figure 9 are correlated by the following equation:

$$
p_{\mathrm{VV}, \text { peak }}=645 \cdot G_{\mathrm{BRK}}^{0.915} \cdot\left(\frac{A_{\mathrm{BRK}}}{A_{\mathrm{RL}}}\right)^{0.915}
$$

Equation (22) is valid for a PHTS saturation pressure of $11.56 \mathrm{MPa}$ and an area ratio in the range $10-150$.

The correlation presents a coefficient of determination $R^{2}$ $=0.9997$, with a standard error of $1.37 \%$. The maximum error is between $-2 \%$ and $+2.8 \%$.

6.2. Sizing the Relief Flow Area: Results and Discussion. To verify the described simplified methodology, the case "B" $\left(600 \mathrm{~m}^{3}\right.$ PHTS) has been simulated with CONSEN, for the considered break area (" $\mathrm{s}$ " $=0.053 \mathrm{~m}^{2}$ and " $\mathrm{d}$ " $=0.11 \mathrm{~m}^{2}$ ), two values of temperature in the ST (293.15 K and $313.15 \mathrm{~K})$, and two different decay heat (5 MW and $20 \mathrm{MW}$ ), according to Table 4.

In Figures 10-15, only results concerning the liquid fraction in the ST $\alpha=0.5$ are reported, as the different ST volumes in the other cases produce very similar results, according to the adopted methodology.

In Figure 10 (break $0.053 \mathrm{~m}^{2}$ ) and Figure 11 (break $0.11 \mathrm{~m}^{2}$ ) the pressure transient in the VV and the ST, for the first $10 \mathrm{~min}$ after the break, is shown (cases B3_s/s2 and B3_d/d2, resp.). In the small frames, the whole transient up to $1 \mathrm{~h}$ after the break shows that, as expected, the final pressure is the same in all the cases $(150 \mathrm{kPa})$.

The rupture disk opens at $1.7 \mathrm{~s}$ for the break " $\mathrm{s}$ " $\left(0.053 \mathrm{~m}^{2}\right)$, and at $0.82 \mathrm{~s}$ for the break " $\mathrm{d}$ " $\left(0.11 \mathrm{~m}^{2}\right)$; the maximum pressure in the $\mathrm{VV}$ occurs between 12 and $13 \mathrm{~s}$ in the first case and 6.5 and $7 \mathrm{~s}$ for the larger break area. The pressure transient is then "accelerated," as expected, increasing the break area, but the final pressure (see also the small frames in Figures 10 and 11) is the same as it depends on the ST volume, selected on the basis of all the parameters involved $\left(2142 \mathrm{~m}^{3}\right.$ for a starting ST temperature of $293.15 \mathrm{~K}$ and a heat source of $5 \mathrm{MW} ; 3115 \mathrm{~m}^{3}$, if the ST temperature is $313.15 \mathrm{~K}$ and a heat source of $20 \mathrm{MW}$ ).

In all the cases the maximum VV pressure is $197-201 \mathrm{kPa}$. This values are equal to the required limit of the VV pressure. After the pressure peak, a minimum pressure is reached at 260-380 s (lower break area) or 130-180 s (larger break area). It can be noted that the higher the initial temperature of the ST and the heat source are (cases "s2" and " $\mathrm{d} 2$ "), the lower the minimum value of pressure in the $\mathrm{VV}$ is: this is a consequence of the higher volume of the ST preliminary evaluated to accommodate the most adverse conditions.

Flow rates and the transient of the mass inventory in the VV are shown in Figures 12 and 13, for the two break area, 
TABLE 4: Sensitivity analyses with the estimated ST volume and relief area.

\begin{tabular}{|c|c|c|c|c|c|c|c|}
\hline Case & PHTS vol. $\mathrm{m}^{3}$ & Break area $\mathrm{m}^{2}$ & Liq. fraction in ST & ST volume $\mathrm{m}^{3}$ & ST temp. K & Decay heat MW & Total relief area $\mathrm{m}^{2}$ \\
\hline B1_s & & & 0.7 & 1534 & & & \\
\hline B2_s & 600 & 0.053 & 0.6 & 1788 & 293.15 & 5 & 3.6 \\
\hline B3_s & & & 0.5 & 2142 & & & \\
\hline B1_s2 & & & 0.7 & 2232 & & & \\
\hline B2_s2 & 600 & 0.053 & 0.6 & 2600 & 313.15 & 20 & 3.6 \\
\hline B3_s2 & & & 0.5 & 3115 & & & \\
\hline B1_d & & & 0.7 & 1534 & & & \\
\hline B2_d & 600 & 0.11 & 0.6 & 1788 & 293.15 & 5 & 7.2 \\
\hline B3_d & & & 0.5 & 2142 & & & \\
\hline B1_d2 & & & 0.7 & 2232 & & & \\
\hline B2_d2 & 600 & 0.11 & 0.6 & 2600 & 313.15 & 20 & 7.2 \\
\hline B3_d2 & & & 0.5 & 3115 & & & \\
\hline
\end{tabular}

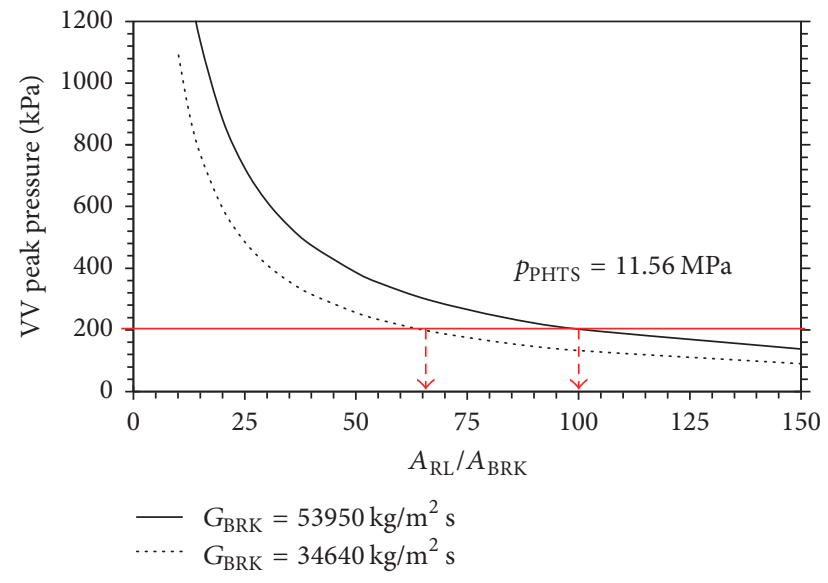

FIGURE 9: Peak pressure in the VV for a WCLL in-vessel LOCA.

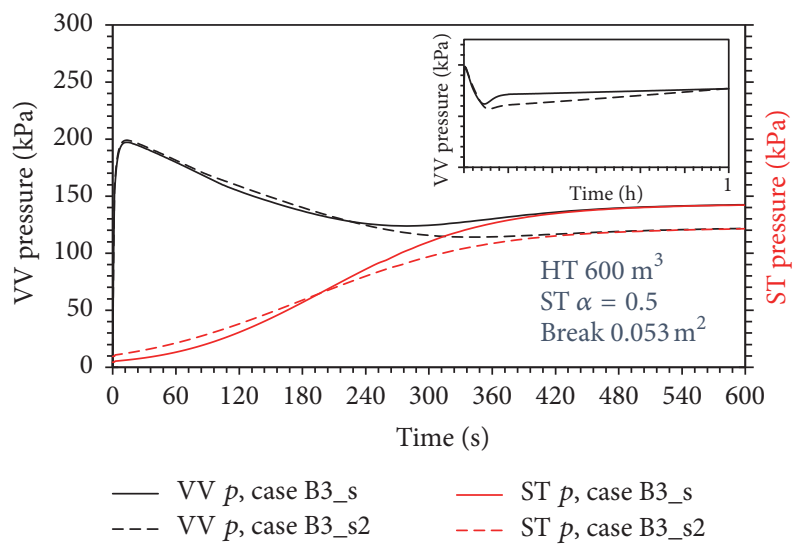

FIGURE 10: VV and ST pressures (smaller break).

respectively; the liquid levels in the ST and VV volumes, calculated by CONSEN as "collapsed" levels but taking into account their simulated geometry (horizontal cylinder), are reported in Figure 14.

The level increment is about $1.1 \mathrm{~m}$ in the VV and $0.5 \mathrm{~m}$ in the ST (its diameter is $5.64 \mathrm{~m}$, and the level changes from

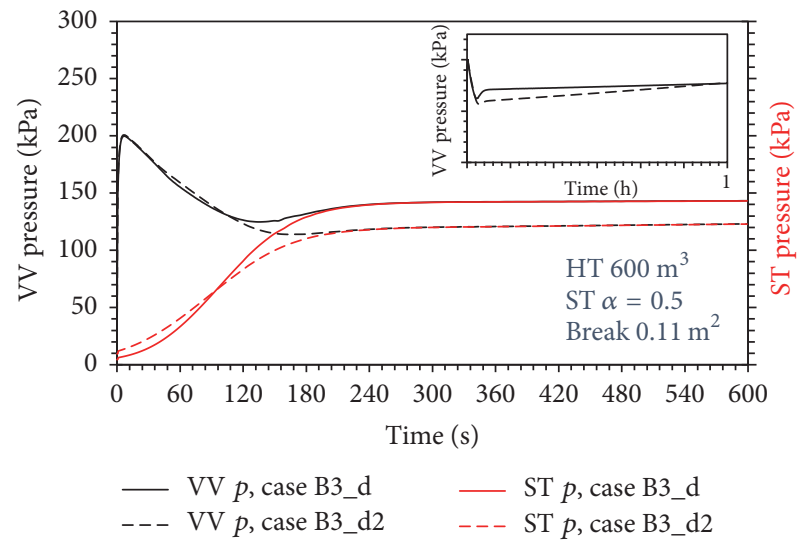

FIGURE 11: VV and ST pressures (larger break).

$2.8 \mathrm{~m}$ to $3.3 \mathrm{~m}$ in the present cases, where the ST is initially filled at 50\%). Therefore, the ST can easily accommodate the water mass transferred from the VV and probably also the level swell during the discharge without excessive mechanical loads on the structure.

Finally, the vapour quality in the VV and the PHTS is shown in Figure 15. The vapour quality in the ST is not included in the figure, because its value is very low (in the order of $10^{-4}$ ), due to the large amount of liquid water in that volume. The vapour quality of PHTS increases in the first minutes after the break, due to the liquid vaporization in the depressurization phase. After 5 or 10 minutes (for the break "d" - $0.11 \mathrm{~m}^{2}$ and for the break "s" - $0.053 \mathrm{~m}^{2}$, resp.), the quality decreases, because mainly steam flows through the break. In the vacuum vessel, after large initial values of the quality due to the water flashing, it decreases because steam is transferred to the ST through the relief pipes.

\section{Conclusions}

A simple methodology to size the suppression tank and the relief pipes for a VVPSS system, to be adopted in a fusion reactor based on WCLL blanket, has been presented. The 


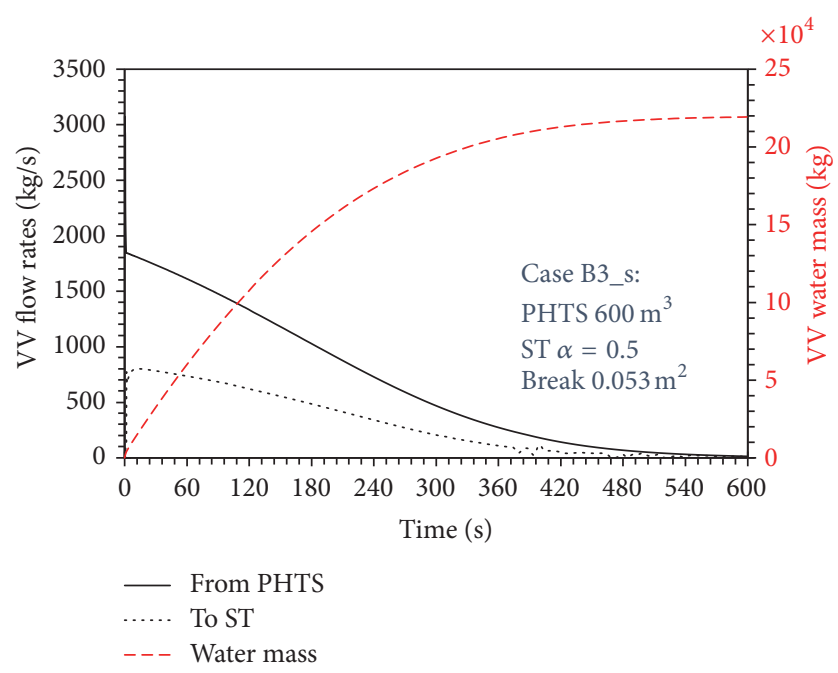

FIGURE 12: Break and relief flow rates and mass inventory in the VV (smaller break).

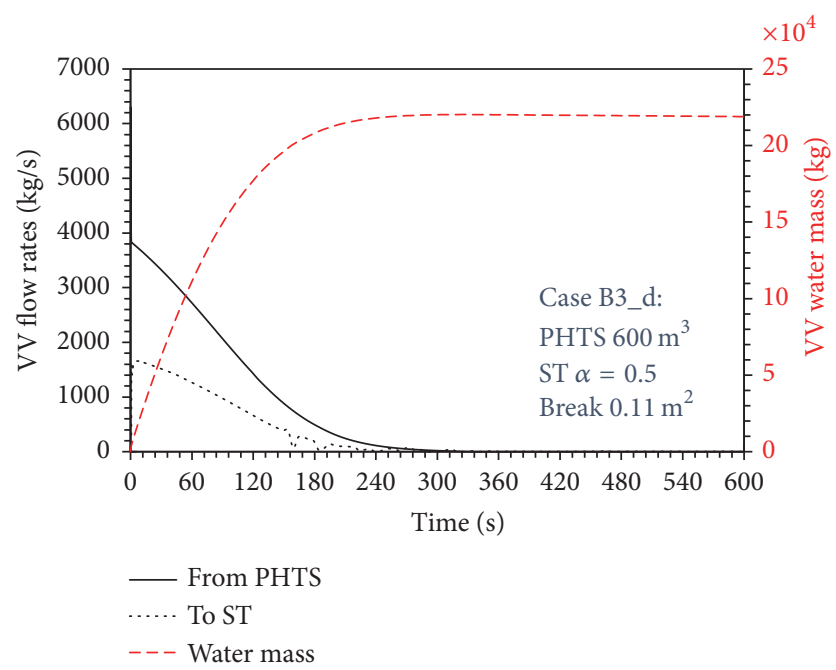

FIGURE 13: Break and relief flow rates and mass inventory in the VV (larger break).

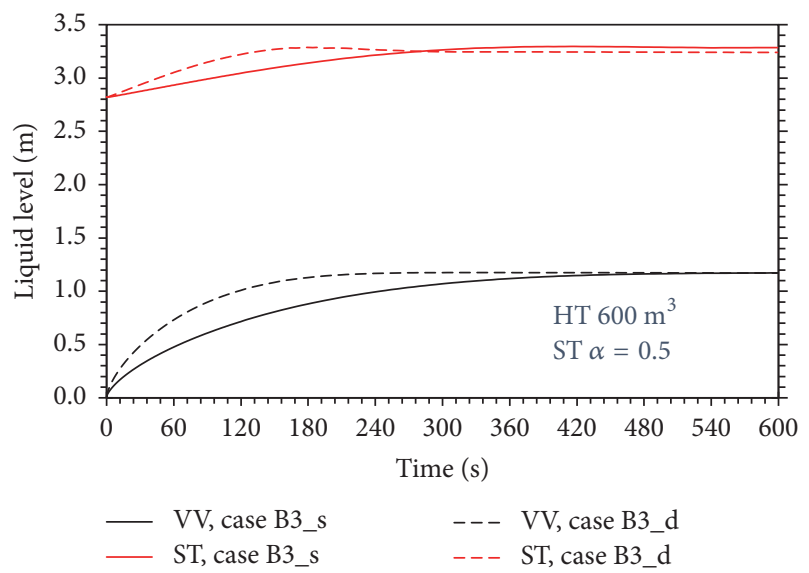

FIgURE 14: Liquid level in the VV and ST.

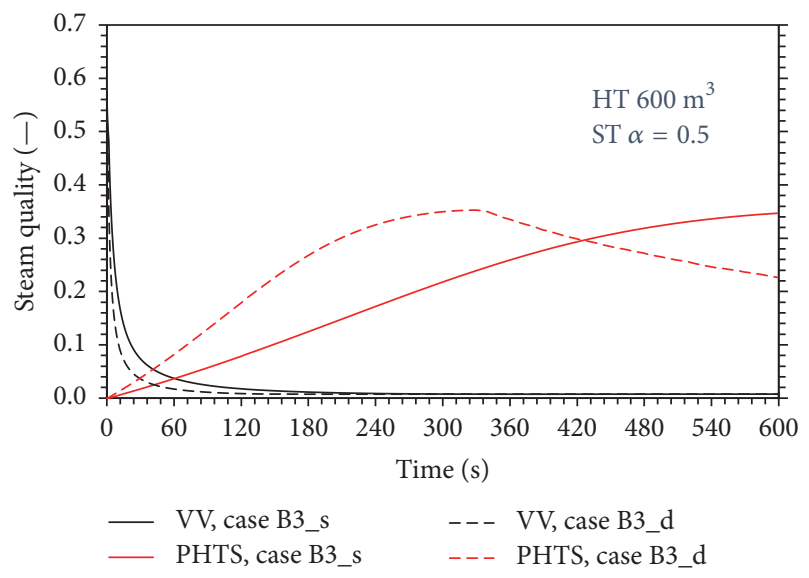

Figure 15: Vapour quality in the VV and PHTS.

procedure can be easily implemented in a spreadsheet to solve the equations iteratively.

The volume of the ST depends on the total energy of the PHTS and it can be sized for a required final pressure at equilibrium, by a simple energy balance. For the assumed thermodynamic conditions of the PHTS (15.5 MPa, max temperature $598.15 \mathrm{~K}$ ) and a supposed volume of the VV $=2240 \mathrm{~m}^{3}$, a simple correlation to evaluate the ST volume varying the ST temperature $(293.15 \mathrm{~K}-313.15 \mathrm{~K})$, the initial liquid fraction (0.5-0.8), the decay heat (5 MW-20 MW), and the volume of the PHTS (300-1000 $\mathrm{m}^{3}$ ) has been developed in these ranges of the parameters. A higher initial liquid fraction in the ST leads to smaller ST volume, but attention must be done to the level swell in the tank during the discharge and the presence of air in the system.

As an example, for a $600 \mathrm{~m}^{3}$ PHTS, a minimum volume of the ST (with an initial liquid fraction of $50 \%$ ) of $2142 \mathrm{~m}^{3}$ is suggested, for $T_{\mathrm{ST}}=293 \mathrm{~K}$ and a heat source of $5 \mathrm{MW}$, but this value increase up to $3115 \mathrm{~m}^{3}$ if the ST temperature is $313 \mathrm{~K}$ and $20 \mathrm{MW}$ heat source. In Table 2, the results of the sensitivity are reported.

The pressure peak in the VV depends mainly from the break area and the flow area of the relief pipes and some suggestions about the method that could be used to size these pipes have been discussed. As a first approximation, to be verified after an accurate evaluation of the mass flux at the break, the minimum total relief area to avoid a peak pressure above $200 \mathrm{kPa}$ (pressure limit for the integrity of the VV and ITER requirement) is $3.5 \mathrm{~m}^{2}$ for a break of $0.053 \mathrm{~m}^{2}$ and $7.2 \mathrm{~m}^{2}$ for a break of $0.11 \mathrm{~m}^{2}$.

The computer code CONSEN has been used to perform parametric analyses and to verify the methodology, getting satisfactory results.

The described methodology can provide a preliminary sizing of the VVPSS system, to be adopted as starting values in the next design phases and for sensitivity calculations, by using validated, but more complex and time-consuming, computer codes.

Therefore, the results provided with this methodology must be carefully verified and they are to be intended just as 
an indication of the system performance in the very preliminary stage of the system design, in absence of reliable input data.

\section{Nomenclature}

A: Flow area, $\mathrm{m}^{2}$

$\alpha$ : Liquid volume fraction

$c_{p}$ : Specific heat, $\mathrm{J} / \mathrm{kg} \mathrm{K}$

$E$ : Internal energy, $\mathrm{J}$

G: Mass velocity, $\mathrm{kg} / \mathrm{m}^{2} \mathrm{~s}$

$\Gamma$ : Mass flow rate, $\mathrm{kg} / \mathrm{s}$

$h$ : Specific enthalpy, $\mathrm{J} / \mathrm{kg}$

$K$ : Pressure drop coefficient, -

$M$ : Mass, $\mathrm{kg}$

$p$ : Pressure, $\mathrm{Pa}$

$\dot{Q}$ : Heat source, W

T: Temperature, $\mathrm{K}$

$t$ : Time, $\mathrm{s}$

$u$ : Specific internal energy, $\mathrm{J} / \mathrm{kg}$

$v$ : Specific volume, $\mathrm{m}^{3} / \mathrm{kg}$

$V$ : Volume, $\mathrm{m}^{3}$

$\omega$ : "Omega" parameter, -

$x$ : Steam quality, -.

\section{Suffixes}

BRK: Break

PHTS: Primary Heat Transfer System

RL: $\quad$ Relief

ST: $\quad$ Suppression tank

VV: Vacuum vessel

$l$ : $\quad$ Liquid

$v$ : Steam

0: $\quad$ Initial state

$f: \quad$ Final state.

\section{Competing Interests}

The authors declare that there is no conflict of interests regarding the publication of this paper.

\section{References}

[1] H. J. Kim, H. C. Kim, M. Kwon et al., "Fusion licensing and safety studies in Korea," IEEE Transactions on Plasma Science, vol. 42, no. 3, pp. 664-670, 2014.

[2] G. Federici, R. Kemp, D. Ward et al., "Overview of EU DEMO design and R\&D activities," Fusion Engineering and Design, vol. 89, no. 7-8, pp. 882-889, 2014.

[3] L. Tong, Y. Li, J. Yu, and X. Cao, "Preliminary analysis of invessel first wall cooling pipe ruptures for ITER," Journal of Fusion Energy, vol. 34, no. 1, pp. 29-35, 2014.

[4] M. Nakamura, K. Watanabe, K. Tobita et al., "Thermohydraulic analysis of accident scenarios of a fusion DEMO reactor based on water-cooled ceramic breeder blanket: analysis of LOCAs and LOVA," IEEE Transactions on Plasma Science, vol. 44, no. 9, pp. 1689-1699, 2016.
[5] M. Nakamura, K. Watanabe, K. Tobita et al., "Progress in thermohydraulic analysis of accident scenarios of a water-cooled fusion DEMO reactor," in Proceedings of the IEEE 26th Symposium on Fusion Engineering (SOFE '15), pp. 1-6, IEEE, Austin, Tex, USA, June 2015.

[6] G. Caruso, F. Giannetti, and M. T. Porfiri, "Modeling of a confinement bypass accident with CONSEN, a fast-running code for safety analyses in fusion reactors," Fusion Engineering and Design, vol. 88, no. 12, pp. 3263-3271, 2013.

[7] G. Caruso, H. W. Bartels, M. Iseli et al., "Simulation of cryogenic He spills as basis for planning of experimental campaign in the EVITA facility," Nuclear Fusion, vol. 46, no. 1, pp. 51-56, 2006.

[8] G. Caruso and M. T. Porfiri, "ICE layer growth on a cryogenic surface in a fusion reactor during a loss of water event," Progress in Nuclear Energy, vol. 78, pp. 173-181, 2015.

[9] P. Sardain, L. Ayrault, G. Laffont et al., "The EVITA programme: experimental and numerical simulation of a fluid ingress in the cryostat of a water-cooled fusion reactor," Fusion Engineering and Design, vol. 75-79, pp. 1265-1269, 2005.

[10] Y. Yamashita, T. Yokomine, S. Ebara, and A. Shimizu, "Ice formation and pressurization under low pressure in cryostat," Fusion Science and Technology, vol. 46, no. 4, pp. 541-546, 2004.

[11] A. Del Nevo, P. Agostini, P. Arena et al., "WCLL breeding blanket design and integration for DEMO 2015: status and perspectives," in Proceedings of the 29th Symposium on Fusion Technology (SOFT '16), Paper O1A.4, Prague, Czech Republic, September 2016.

[12] J. C. Leung, "Easily size relief devices and piping for two-phase flow," Chemical Engineering Progress, vol. 92, no. 12, pp. 28-50, 1996. 

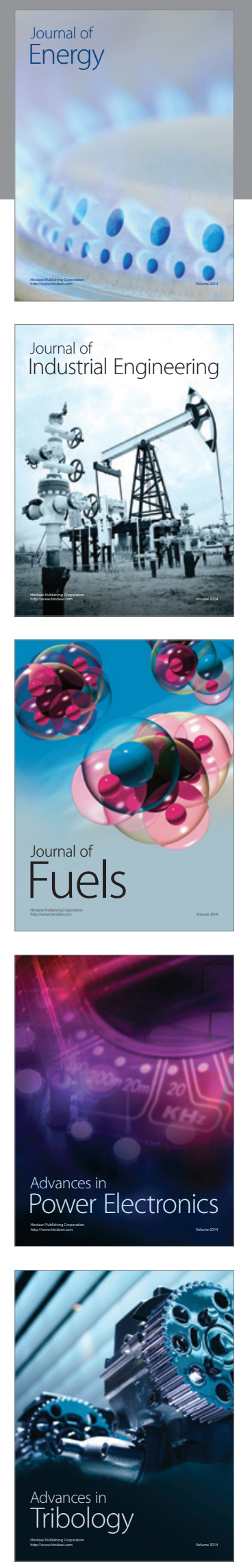
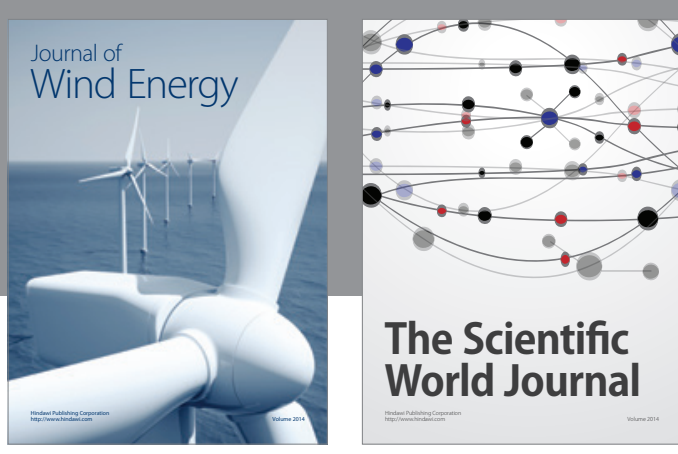

The Scientific World Journal
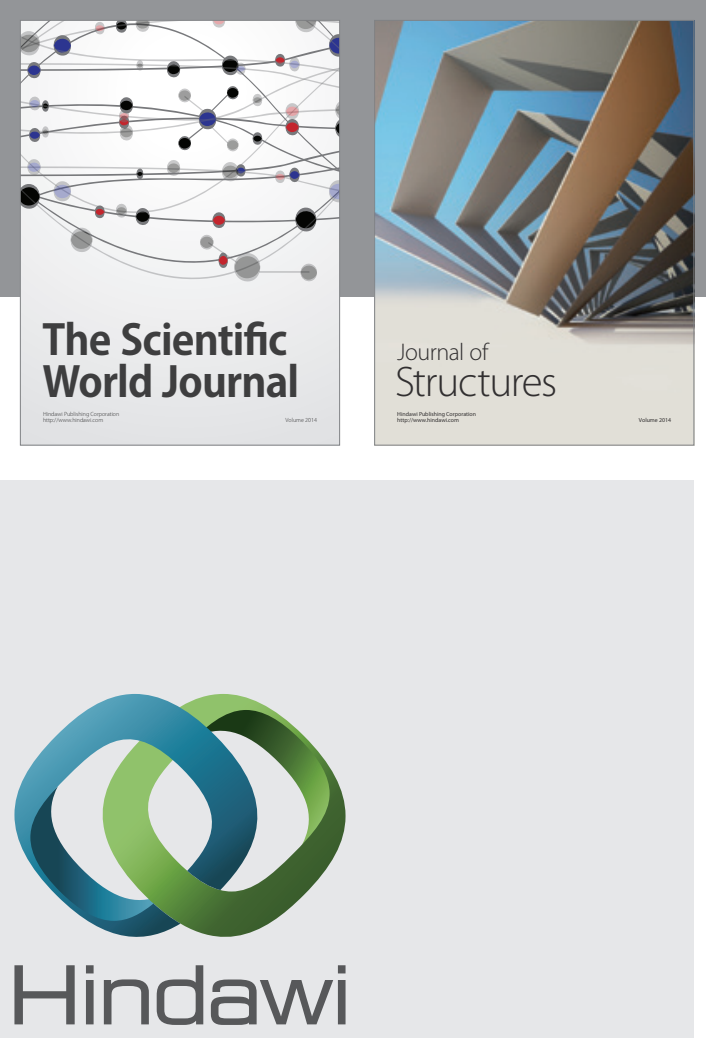

Submit your manuscripts at

http://www.hindawi.com
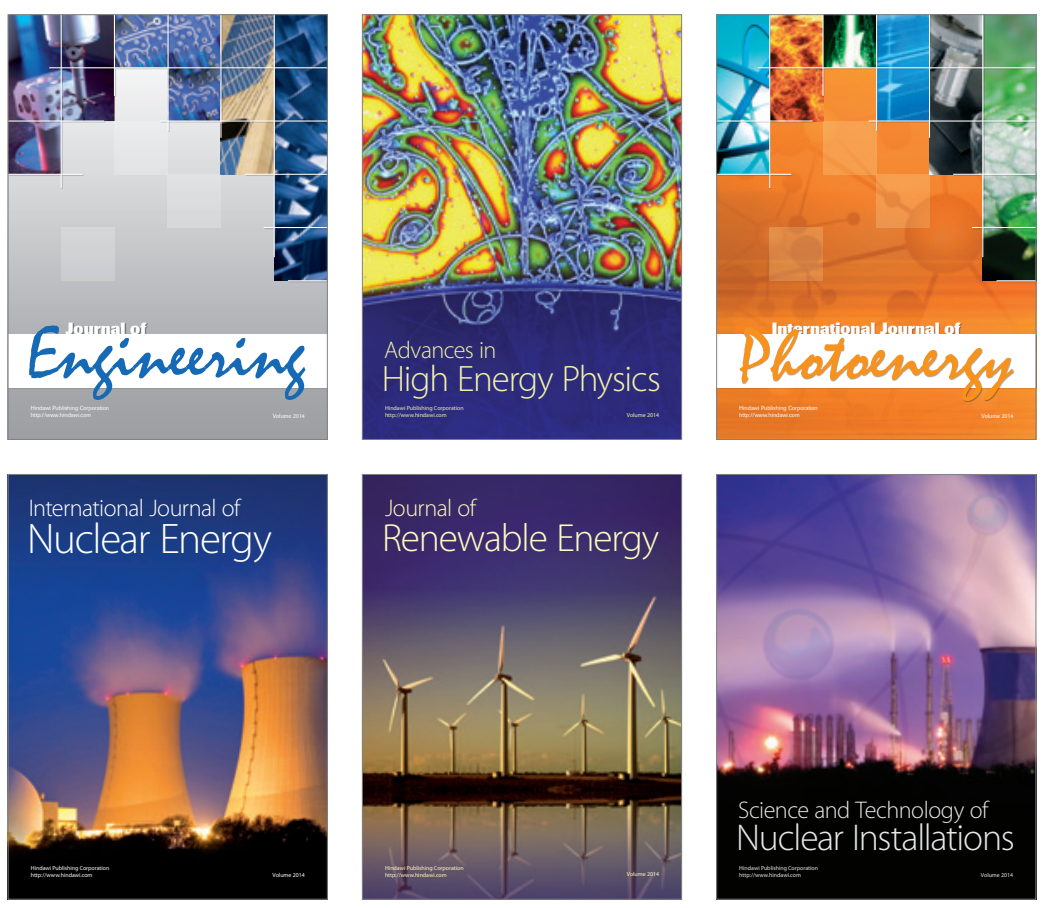
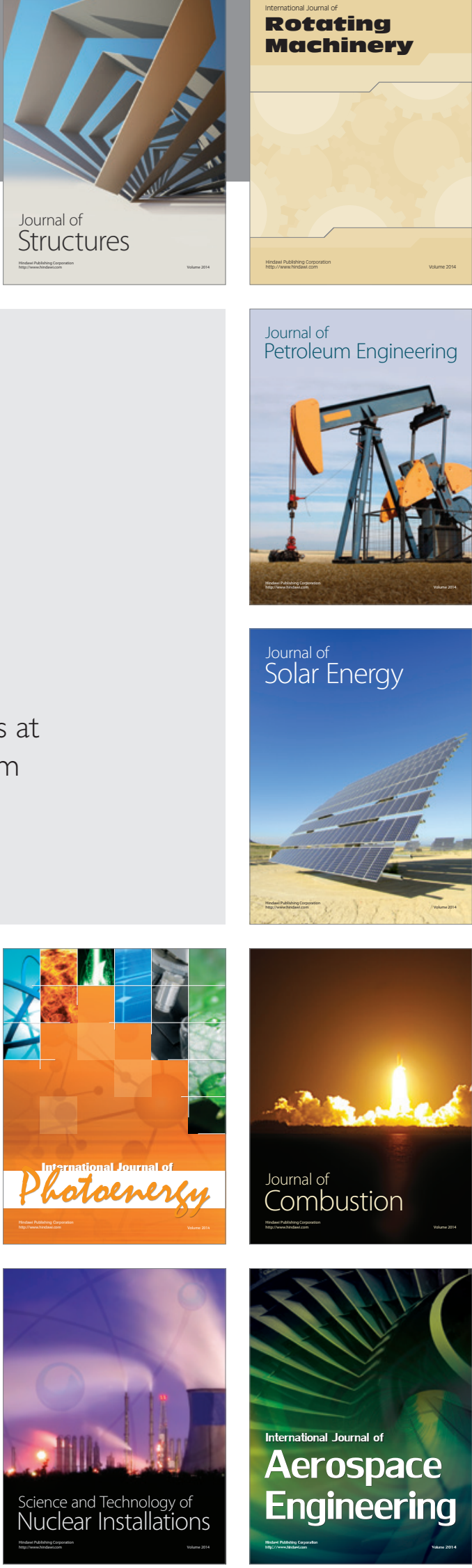